\title{
Perancangan Game Batik "Nitiki" Berteknologi Multi-Touch Screen
}

\author{
Chandra Tresnadi ${ }^{1}, \operatorname{Irfansyah}^{1} \&$ Ary S. Prihatmanto ${ }^{2}$ \\ ${ }^{1}$ Fakultas Senirupa \& Desain ITB \\ ${ }^{2}$ Sekolah Teknik Elektro dan Informatika ITB
}

\begin{abstract}
Batik is an intangible cultural heritage of Indonesia that has endured a span of 200 years in its existence. Batik may enter today's contemporary world by exploiting both the traditional and contemporary cultures to look beyond what has been elaborated before. Having exposed to the world of digital game and animation, this study exploited multi-touch screen technology to develop a new game-play on Javanese batiks as a visual entertainment medium to serve learning of batik. Using gesture interactivity sensors, the game of batik was designed by allowing users to interact freely with the contents limiting the mechanistic control in game playing. The end-result showed that traditional artifact, such as batik, can be exposed in a new technological medium. The game of batik serves as an alternate way to suit traditional knowledge into the contemporary world we live in.
\end{abstract}

Keywords: batik; game design; multi-touch screen; interactivity.

\section{Pendahuluan}

Penelitian terhadap dunia batik telah banyak dilakukan baik di lingkungan ilmiah, pemerintah, ataupun instansi terkait berupa pembahasan seputar sejarah, motif, teknik produksi, pemasaran, pengembangan batik sebagai produk akhir, dan penelitian batik sebagai objek kajian dalam pembentukan citra pada media rupa seperti komunikasi visual, produk, interior, arsitektur, dan keilmuan lain. Misalnya penelitian yang membahas tentang simbol pada batik dan kaitannya terhadap upacara adat di suatu daerah oleh Umar Kayam [1] atau penelitian tentang pergeseran fungsi ragam hias batik [2].

Penelitian tersebut secara umum bersifat sebagai wacana penelitian dan sedikit ditemukan judul penelitian yang bersifat terapan untuk dirasakan langsung manfaatnya oleh masyarakat yang bersangkutan. Projek penelitian berobjek batik ke depan seyogyanya bersifat memiliki wacana keilmuan yang mendalam dan mampu diterapkan hasil karyanya pada masyarakat luas baik secara komunikasi, interaksi produk, penempatan yang berhubungan dengan interior dan arsitektur pada sebuah lingkungan. 
Penelitian yang melibatkan dunia batik tradisional di pulau Jawa kemudian menjadi akar pembahasan dari permasalahan yang timbul akibat batik tradisional di pulau Jawa mulai tersisihkan secara perhatian walaupun data yang dirangkum oleh Depkominfo mengatakan bahwa industri batik diakui sebagai sumber devisa negara non migas. Pada 2006 jumlah industri batik mencapai 48.287 unit usaha dan menyerap 792.300 orang tenaga kerja dengan nilai produksi Rp 2,9 triliun dan nilai ekspor sekitar 110 juta dolar AS. Terdapat 17 provinsi sebagai lokasi produsen batik utama di Indonesia, seperti: Jambi, Palembang, Bengkulu, Jakarta, Banten, Jawa Barat, Jawa Tengah, Yogyakarta, Jawa Timur, Bali, Sumatera Barat, Lampung, Kalimantan Barat, Kalimantan Selatan, Kalimantan Timur, Sulawesi Selatan, dan Papua [3].

Di sisi lain perkembangan dunia teknologi komputer modern melaju pesat. Fenomena tersebut kemudian dipilih sebagai studi kasus dalam upaya penggabungan dunia batik (budaya tradisi) terhadap perkembangan teknologi komputer modern melalui media game digital (produk teknologi komputer) yang dianggap mampu menjadi penyampai informasi tentang budaya tradisi (batik). Penelitian dapat dikategorikan sebagai upaya untuk turut melestarikan dan mengembangkan batik ke taraf persinggungan langsung dengan perkembangan teknologi komputer, game digital, serta interaksinya dengan masyarakat.

Batik tradisional di pulau Jawa mengandung pengertian, pertama: mengacu pada karya batik yang dikerjakan di pulau Jawa seperti di Jakarta, Garut, Tasikmalaya, Ciamis, Cirebon, Indramayu, Banyumas, Pekalongan, Semarang, Solo, Yogyakarta, Lasem, Surabaya, hingga di Madura; kedua: mengacu pada penerapan motif khas yang turun-temurun ada dan dikembangkan di pulau Jawa seperti motif Parang, Nitik, Kawung, Liris, Semen, Patran, Buketan, Pagi-Sore, Ceplok, dan sebagainya. Batik tradisional di pulau Jawa meliputi keragaman pada proses produksi seperti persiapan alat dan bahan, men-canting, men-cap, menyelup-mewarnai, menghilangkan malam dan penggunaan motif pada kain, penggunaan kain batik dalam kegiatan harian dan seterusnya yang diwakili oleh lima daerah penghasil kain batik di pulau Jawa seperti Garut, Cirebon, Pekalongan, Solo, Yogyakarta, dan Madura sebagai daerah yang masih aktif hingga kini sebagai daerah penghasil kain batik [4].

Persamaan dan perbedaan sebagai pembentuk karakteristik pada tiap-tiap daerah penghasil kain batik menjadi data utama dalam proses perancangan game digital yang meliputi gaya rupa, citra warna, garis, bentuk, kemampuan detil, dan persepsi pemaknaan suatu objek menjadi data yang perlu diolah, dianalisa, dan disusun menjadi bentuk baru dunia batik dalam media game digital yang didukung oleh teknologi multi-touch screen. 
Game digital merupakan sebuah respon terhadap perkembangan teknologi komputer sejak Willy Higinbotham menciptakan "the tennis program" disebut juga Pong Game di komputer analog pada tahun 1958 [5]. Game digital pada perkembangannya bertransformasi menjadi pro-kontra di wacana ekonomi, hiburan, teknologi, budaya, dan sebagainya yang di dalamnya terkandung pesan, informasi, tujuan, serta dampak yang beragam terhadap permasalahan sosial, politik, ekonomi, moral, psikologi, dan budaya itu sendiri seperti yang sering diulas dalam forum-forum tentang dunia game ataupun budayawan, sosiolog, psikolog yang menjadikan game sebagai objek studi penelitiannya [6].

Pro-kontra game digital dan permasalahan yang melingkupi batik tradisional di pulau Jawa memiliki keterkaitan untuk saling mendukung dan mengarahkan pemikiran tentang upaya melestarikan batik melalui media game digital dan sebaliknya memberikan muatan informasi pendidikan positif pada sebuah desain game digital untuk dikonsumsi oleh masyarakat game dan non game.

Pengembangan penelitian ini mengarah pada sebuah desain game digital dengan nuansa baru bergenre simulation participatory sebagai mekanisme untuk menentukan gameplay dan interactivity yang berbeda pada tiap fase cerita namun tidak menghilangkan tiga kebutuhan dasar sebuah game seperti yang dikutip oleh Rouse Richard III dari Dr. Rigby Scott [7], peneliti tentang game terhadap dampak interaksi sosial, yaitu: autonomy (memilih), mastery (perasaan), social interaction (interaksi sosial). Penelitian ini didukung oleh teknologi komputer tepat guna untuk mampu menjembatani tiga kebutuhan dasar perancangan game di atas dan tidak menghilangkan esensi dasar dunia batik yang mengedepankan rasa dan keterampilan sentuhan tangan.

Teknologi tersebut berupa teknologi berbasis multi-touch screen yang dipelopori oleh Jeff Han pada konferensi TED, 2006. Teknologi multitouchscreen merupakan teknologi masa depan hasil dari pengembangan teknologi komputer dan metoda sensor sebagai bidang terapan baru pada perangkat elektronik di negara-negara maju. Di Indonesia teknologi multitouchscreen baru diminati oleh beberapa individu (ra-kreasi dan neway, keduanya dari Bandung) yang telah menghasilkan produk nyata berupa konsol multi-touch screen aktif dan institusi pendidikan seperti ITB yang semuanya masih dalam tahapan penelitian.

Keterbatasan tenaga ahli di teknologi multi-touchscreen di Indonesia dianggap sebagai peluang untuk memberikan kontribusi pada kegunaan teknologi tersebut pada penelitian dan perancangan game digital bermuatan dan berkarakter dunia batik tradisional di pulau Jawa. 
Sifat dan karakter teknologi multi-touchscreen yang berdasarkan metoda gesture interactive (gerak, cahaya, bayangan, suara, getaran) dapat memberikan pengaruh terhadap perancangan desain game. Dengan kemampuan teknologi multi-touchscreen yang demikian maka menjadi perlu untuk memilih salah satu unsur yang ada di dunia batik tradisional di pulau Jawa sebagai tema pembangun cerita game, gameplay, sekaligus sebagai memusatkan bahasan penelitian, yaitu: proses pembuatan batik (mencanting, mencap, mewarnai, dan penghilangan malam) sebagai medium yang dianggap sesuai dengan mekanisme kerja teknologi multi-touchscreen yang berbasis sentuhan jari dan tangan pada layar monitor konsol.

Penelitian berjudul Perancangan Game Batik "NITIKI" Berteknologi MultiTouch Screen adalah upaya di lingkungan formal strata pascasarjana dalam menggabungkan beberapa terapan disiplin ilmu (batik=seni rupa tradisi, game=sosial komunikasi, seni rupa modern, multi-touch screen=teknologi komputer masa depan) untuk menelisik dunia batik tradisional di pulau Jawa meliputi kaidah produksi, motif, dan elemen lainnya untuk diolah sebagai muatan tema utama dalam perancangan game digital berteknologi multi-touch screen. Penelitian diharapkan menjadi sebuah alternatif penyampai informasi pendidikan yang dibatasi oleh kepentingan hiburan dan pendidikan interaktif sederhana untuk masyarakat sehingga dapat tersebar luas secara ringan agar menggairahkan minat masyarakat untuk belajar mengenal (dunia) batik sebagai warisan budaya di Indonesia tanpa menghilangkan kandungan nilai dan visual yang ada di dunia batik tradisonal di pulau Jawa.

\section{Konsep Dasar Game Batik "NITIKI"}

Game Batik "NITIKI" adalah game simulasi yang dirancang dengan metoda participatory (berhubungan dengan partisipasi, keterlibatan), yaitu melibatkan emosi, indera (mata, telinga, raba, naluri), dan aktifitas fisik pemain yang menjadi faktor penting dalam membangun interaktivitas gameplay terhadap pemain dan lingkungan [5]. Metoda ini telah dikembangkan di negara barat sebagai sebuah metoda baru untuk dimasukkan sebagai mekanisme utama dalam perancangan game digital, seperti produk-produk game dan konsol keluaran Nintendo (wii), dan Eye Toy yang dapat dimainkan di konsol Sony PlayStasion 2 dan 3.

The concept of participatory games is the same of interactive storytelling presented by Glassner, 2004.

However, we prefer the term "participatory game" to emphasize the focus on games rather than on storytelling. In this paper, we use the term "interactive storytelling" when the focus is on story generation and dramatization. Participatory games can also be identified in the New concept of alternate 
reality gaming $(A R G)^{*}$, which blends real-world activities and a dramatic storyline (Szulborski, 2005) (Borland, 2005).

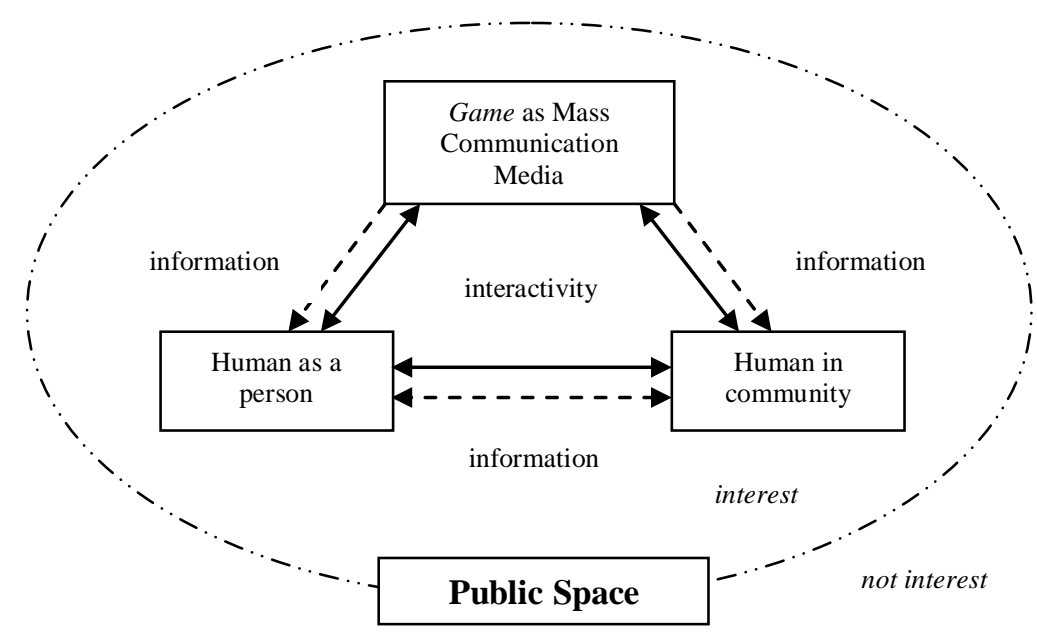

Bagan 1 Pola interaksi pada ruang publik antara: manusia terhadap game sebagai media komunikasi massa, manusia dengan manusia lain dalam kelompok, manusia dalam kelompok terhadap game yang saling memberikan jalur informasi.

Bagan di atas menjelaskan interaksi antara game sebagai pusat media komunikasi/informasi massa pada ruang publik memberikan aksi-reaksi kepada satu orang, diikuti interaksi beberapa orang terhadap konsol, dan terakhir orangperseorangan saling berinteraksi dengan sekelompok orang yang lain terhadap satu konsol game di satu tempat dalam waktu yang bersamaan dan disebut sebagai sekelompok yang tertarik dan terikat dengan konsol yang masuk dalam wilayah area publik (pusat perbelanjaan, terminal transportasi, lobi instansi pemerintahan/swasta, museum, hotel). Di luar area publik yang termasuk perorangan atau sekumpulan orang yang tidak turut berinteraksi (penonton) atau yang tidak disebut sebagai yang tidak tertarik dan atau terikat oleh kegiatan game konsol tersebut.

Respon satu atau beberapa pengunjung terhadap konsol dengan melakukan sentuhan fisik manusia yaitu jari hingga telapak tangan pada permukaan layar adalah cara yang diberlakukan sebagai kontrol pemain terhadap permainan. Jenis sentuhan tergantung dari bagian yang ditampilkan oleh game tersebut dengan telah melalui proses penyederhanaan teori, citra rupa, dan pemaknaan batik dengan memperhatikan kesesuaian pada proses kreasi perancangan game, cerita, dan estetika yang tetap menjaga pola informasi untuk pemain akan proses kreasi batik pemalaman tulis $\rightarrow$ pemalaman cap $\rightarrow$ pewarnaan $\rightarrow$ penghilangan malam. 
NITIKI, berasal dari bahasa Jawa nitik yang artinya memberi titik dan dengan diberi imbuhan $-i$ maka secara sengaja memberi penegasan terhadap kegiatan member titik yang berulang dan terus-menerus. Sehingga NITIKI dapat diartikan sebagai kegiatan memberi, membuat banyak titik pada suatu objek material secara berulang dan terus-menerus. NITIKI sangat dekat dengan kata mbatik yang dalam bahasa Jawa mengacu pada pengertian ngembat (melempar) titik, yaitu kegiatan memberi titik pada kain dengan malam sebagai perintang warna seperti yang dituturkan oleh Amri Yahya dalam sebuah makalah seminar [8]. Nitik di sisi lain merupakan sebuah pola motif khas batik yang termasuk jenis motif asli dan tertua (lihat Gambar 1), motif nitik ini berkembang di daerah Yogyakarta dan Pekalongan (disebut juga sebagai motif Jlamprang) dan termasuk dalam kelas pola geometris[9].

Berikut adalah nama-nama motif Nitik menurut Susanto [10], yaitu: Rengganis, N. Krawitan, N. Jonggrong, N. Pijetan, Cakar Melik, Jaya Sentana, N. Gendangan, N. Cakar Wok, N, Onengan, N. Sulaman, N. Yuyu, N. Ragahina, N. Kembang Sikatan, N. Kembang Kacang, N. Kembang Blimbing, N. Banci Kasut, N. Tunjung Gunung, N. Ceplok Liring, Tirta Teja Alit, Tirta Teja Ageng, dan Cinden Yogyakarta.
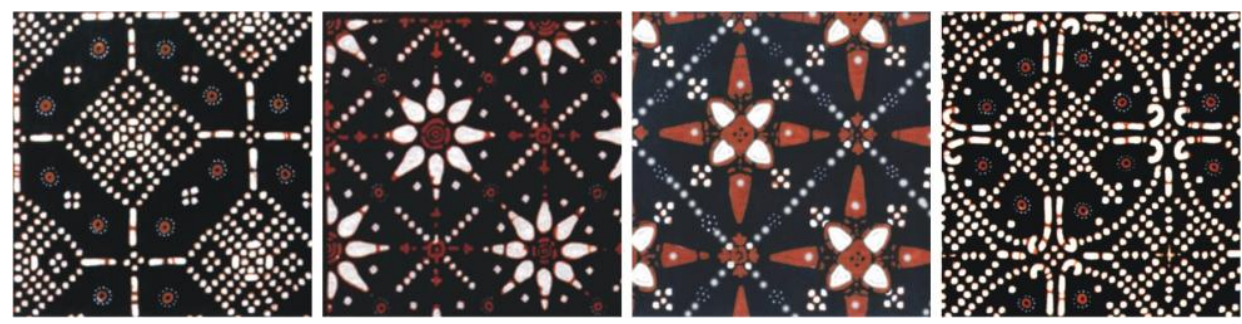

Gambar 1 Pola motif Nitik Wora-wari Rumpuk, N. Teruntum Kurung, N. Sri Taman Melik, dan N. Sekar Soka karya Maria Noor, 2003 dari Yogyakarta warna sogan tua dan merah mengkudu [11].

\section{$3 \quad$ Sistem Level Game Batik "NITIKI"}

Sebuah game pada dasarnya memiliki konsep sistem level to level untuk dapat dimainkan hingga selesai. Akan tetapi sitematika level pada perkembangan desain game dewasa ini tidak melulu menerapkan sistem tersebut, bahkan ada desain game yang sifatnya datar tanpa level yang jelas melainkan digeser kepada pemanfaatan hasrat pemain untuk selalu menyelesaikan cerita atau tugas yang diberikan oleh gameplay. Game dengan sistem datar banyak diadaptasi oleh keluaran terbaru seperti Ragnarok on Line, Counter Strike, Aquanauts Holiday, dan sebagainya. 
Sistem leveling pada game NITIKI tidak menggunakan sistem leveling seperti pada umumnya yang mengandung runut (level 1, 2, dan 3) namun disesuaikan menjadi sistem phase (bagian) dengan mengacu pada runut sesuai proses membuat batik.

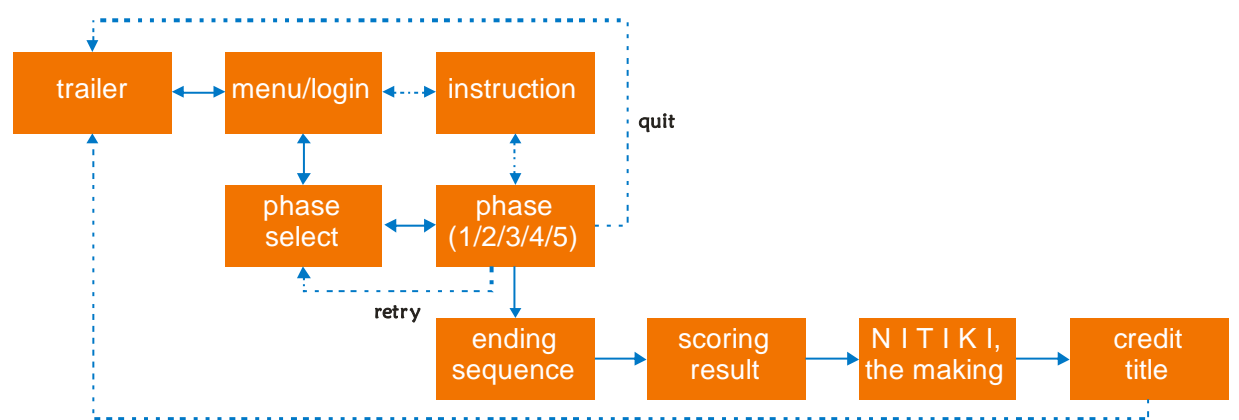

Bagan 2 Pola interaksi Game NITIKI dengan proses pembuatan batik sebagai tema gameplay.

Pola fase pada game NITIKI yang dibangun menurut pada proses pembuatan batik yaitu: diawali oleh tampilan animasi trailer game $\rightarrow$ Menu utama (login) $\rightarrow$ animasi game story/how to play (tutorial/instruction) $\rightarrow$ selanjutnya berupa:

Bagian 1 (tulis): kegiatan memberikan garis luar atau titik sebagai isen pada bidang atau bentuk yang muncul pada layar sesuai perintah. Bidang atau bentuk tersebut akan selalu bergerak dinamis, menghilang, mengecil/membesar, menjauh/mendekat; setiap tugas yang selesai maka objek akan bertransformasi menjadi animasi (misalkan: bentuk burung yang selesai di batik akan berubah bergerak dinamis-seperti hidup).

Bagian 2 (cap): menarik puzzle objek motif berwarna yang bergerak dinamis untuk disusun sesuai objek yang sama berupa garis luar. puzzle-puzzle tersebut mengandung pola motif dan memiliki sifat licin, alot, hingga hiperaktif;

Bagian 3 (colet): menarik balon berwarna tertentu untuk ditempatkan pada bidang tertentu di kain bermotif dan dipecahkan untuk memberikan warna pada kain tersebut;

Bagian 4 (lorod): menghapus malam pada kain dengan menggerakkan telapak tangan pada permukaan layar sesuai acuan gerak yang diminta pada ikon di layar (misalnya pola gerak zig-zag, patah-patah, gelombang, putaran, silang, ceplok).

Ditutup oleh Final Results $\rightarrow$ Award Event $\rightarrow$ Credits Title $\rightarrow$ The End. 


\section{Karakter Batik pada Tampilan Game Batik "NITIKI"}

Karakter pembentuk visual dalam sebuah game digital menjadi penting karena berhubungan terhadap citra game, persepsi, target audiens, dan daya tarik utama pengguna pada produk desain game. Game Batik NITIKI menggunakan beberapa contoh awal karakter dan gaya visual yang ada pada kain-kain batik tradisional di pulau Jawa untuk dirancang ulang dengan tetap memerhatikan kaidah karakteristik batik berupa detil titik-titik (isen) dan garis luar bidang berwarna putih atau coklat malam (wax). Penyederhanaan terhadap objek motif asli, garis, bidang, detil, tekstur, dan warna menjadi perhatian penuh dalam proses re-desain untuk memenuhi kategori target pemain usia 12 tahun ke atas. Game Batik NITIKI kemudian menggunakan citra rupa datar sebagai gaya representasi dari citra rupa batik yang lugas dan ornamentik.

Pengumpulan library atau data gambar berupa sketsa (karakter, ikon, objek utama, latar, teks, logo, dan sebagainya) dilakukan dengan cara mengumpulkan data-data gambar dari kain batik tradional ataupun berupa foto kain batik dari lima daerah, diklasifikasikan, disortir citraan yang terdapat pada kain-kain tersebut dan disesuaikan dengan identifikasi citra yang dimaksud pada naskah game NITIKI yaitu objek-objek berbentuk tumbuhan, bunga, sulur, hewan, dan lay out yang dapat diolah menjadi bentukan baru bernuansa batik tradisional dan sesuai dengan konsep target audiens (Gambar 2 dan 3).

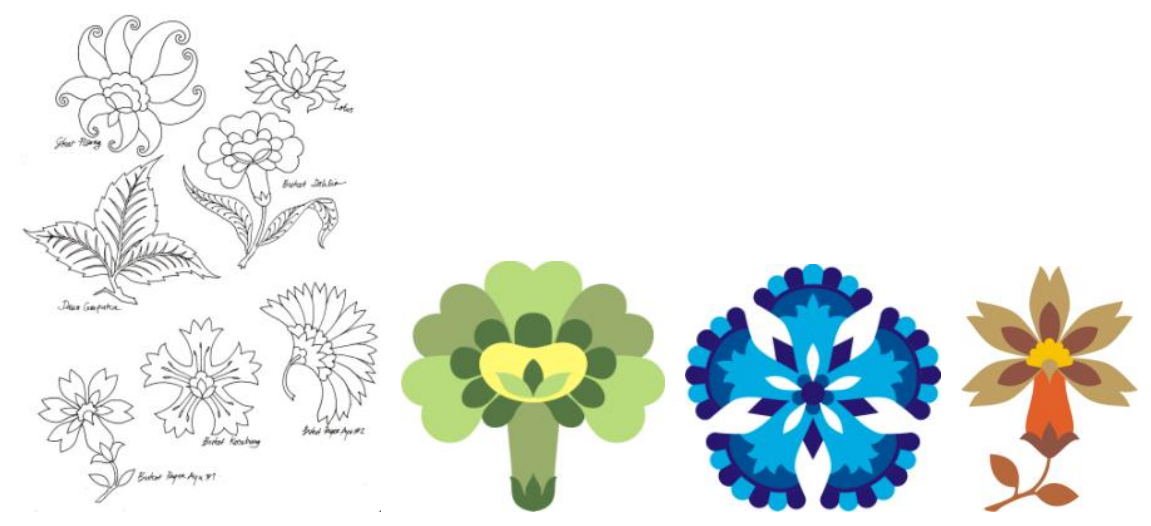

Gambar 2 (ki-ka): Desain motif tumbuhan Buket Dahlia-Pekalongan, Sekar Cempaka-Solo, Buket Pager Ayu-Pekalongan yang menjadi inspirasi dan distilir menjadi objek pada game NITIKI. ( [10] dan dokumen pribadi). 


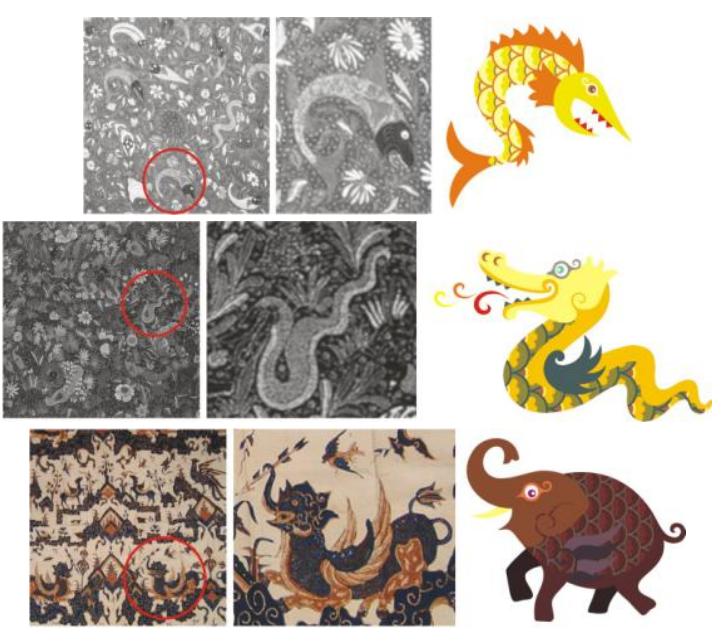

Gambar 3 (ki-ka): Proses perancangan desain motif hewan ikan, naga, dan gajah bersayap dari citra rupa yang terdapat pada sepotong kain batik berjudul Alas-alasan karya Danar Hadi-Solo, dan Paksi Naga Liman karya MasinaCirebon. Citra tersebut menjadi inspirasi yang distilir menjadi objek pada game NITIKI. ([11] dan dokumen pribadi).

\section{Gameplay Game Batik "NITIKI" dan Teknologi Multi-Touch Screen}

The gameplay is the component of computer game which is found in no other form interactivity. A games play is the degree and nature of the interactivity that the game includes, i.e., how the player able to interact whith the game world and how that the game-world can react to choice the player makes [7].

Pengertian gameplay dapat dipadankan pada pengertian jalan cerita di wilayah perfilman hanya saja gameplay berfungsi sebagai parameter aksi-reaksi yang terjadi selama game dimainkan. Sensitivitas, keakuratan aksi dengan gerak visual dan suara menjadi keberhasilan sebuah gameplay dalam desain game digital.

Gameplay berisi tentang alur cerita, menu, setting, mekanisme kontrol, dan informasi lainnya yang memberikan tiga kebutuhan dasar sebuah desain game (autonomy, mastery, social interaction).

Perancangan gameplay NITIKI didukung oleh teknologi komputer berbasis sensor gerakan dan sentuhan pada layar konsol yang memberikan batasan sekaligus keleuasaan dalam mengeksplorasi sentuhan. Teknologi yang diterapkan adalah teknologi multi-touch screen dengan metoda FTIR (Frustated Total Internal Reflection). Teknologi ini bekerja karena adanya aksi dari 
gerakan dan sentuhan pada layar yang telah diperlakukan khusus dan ditangkap oleh seperangkat lampu led ID, webcam yang tersambung pada komputer, dan ditelaah oleh program lunak khusus dan memberikan reaksi yang dipancarakan melalui proyektor ke layar konsol yang ditangkap visualnya oleh mata pengguna.

Teknologi multi-touch screen dipilih karena mekanisme sentuhan yang dianggap sebagai teknologi yang mampu merepresentasikan mekanisme kerja pembuatan batik tradisional di pulau Jawa ke dalam bentuk game digital. Dengan cara kerja yang dimiliki oleh konsol dan teknologi multi-touch screen, perancangan desain game batik NITIKI dapat mendekati pada metoda simulasi, participatory, dan performity yang dimaksudkan dalam konsep awal perancangan game digital yang menggunakan batik sebagai tema utama.

Pemain harus berani mendekat, berinterkasi terhadap konsol game, berinteraksi terhadap gameplay, dan berinteraksi terhadap pemain lain dan lingkungannya sebagai bentuk partisipasi yang membentuk sebuah kegiatan performing yang dapat disaksikan oleh publik di mana konsol game tersebut berada (Gambar 4 dan 5).

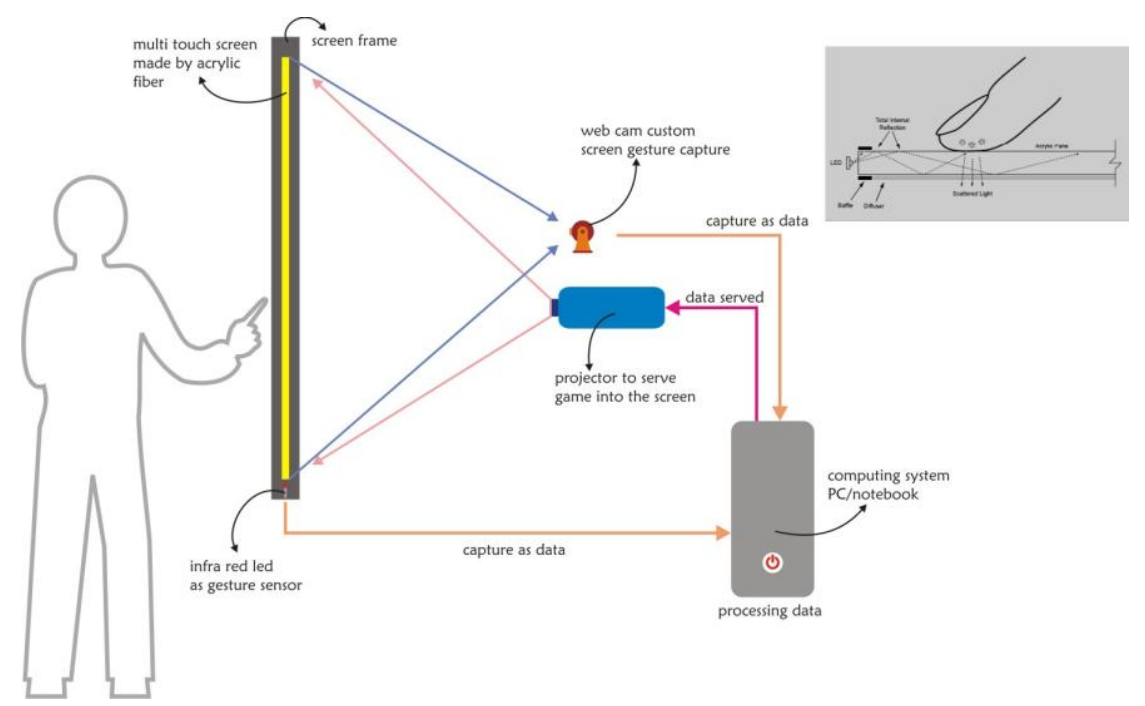

Gambar 4 Alur kerja teknologi multi-touch screen. Aksi sentuhan (satu atau banyak sentuhan) akan direspon oleh konsol dengan sensitivitas yang akurat sehingga memberikan reaksi sentuhan dan menyampaikan pesan yang akan di aksikan kembali oleh pemakai konsol tersebut. (dokumen pribadi) 


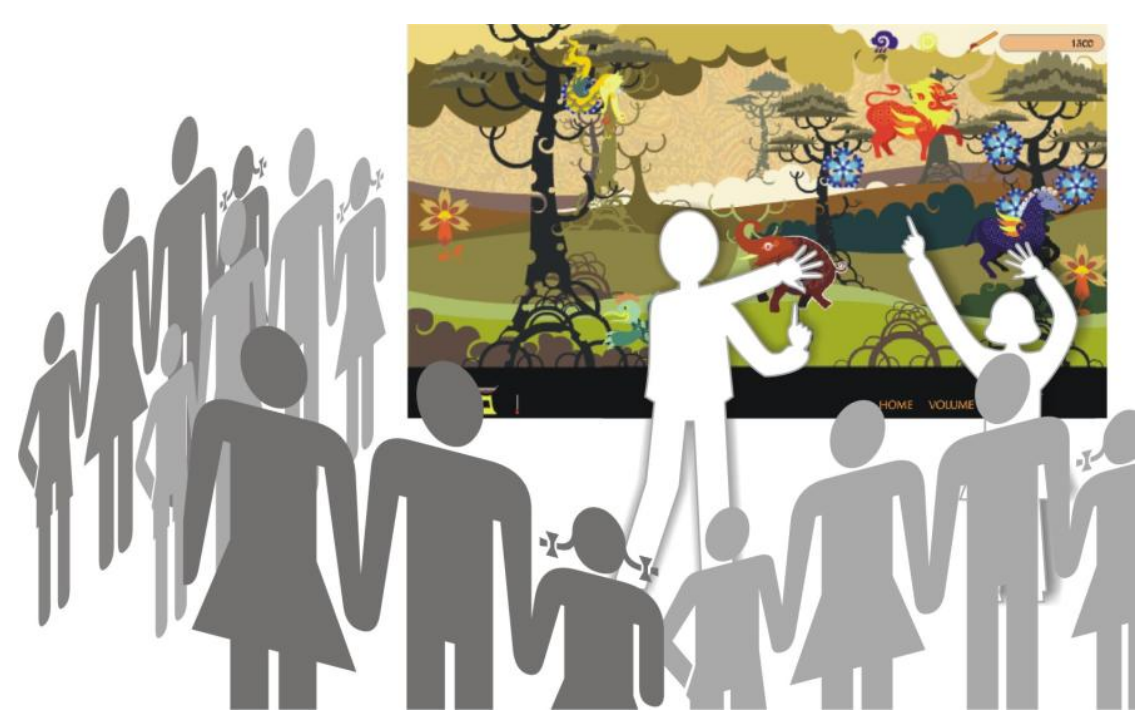

Gambar 5 Tampak simulasi cara bermain dan peletakan konsol Game Batik "NITIKI" berteknologi Multi-Touch Screen pada ruang publik. (dokumen pribadi)

Berikut (Gambar 6) adalah beberapa screen shot game batik NITIKI dan penjelasannya dari menu login pembuka hingga fase terakhir sebagai pembentuk gameplay:
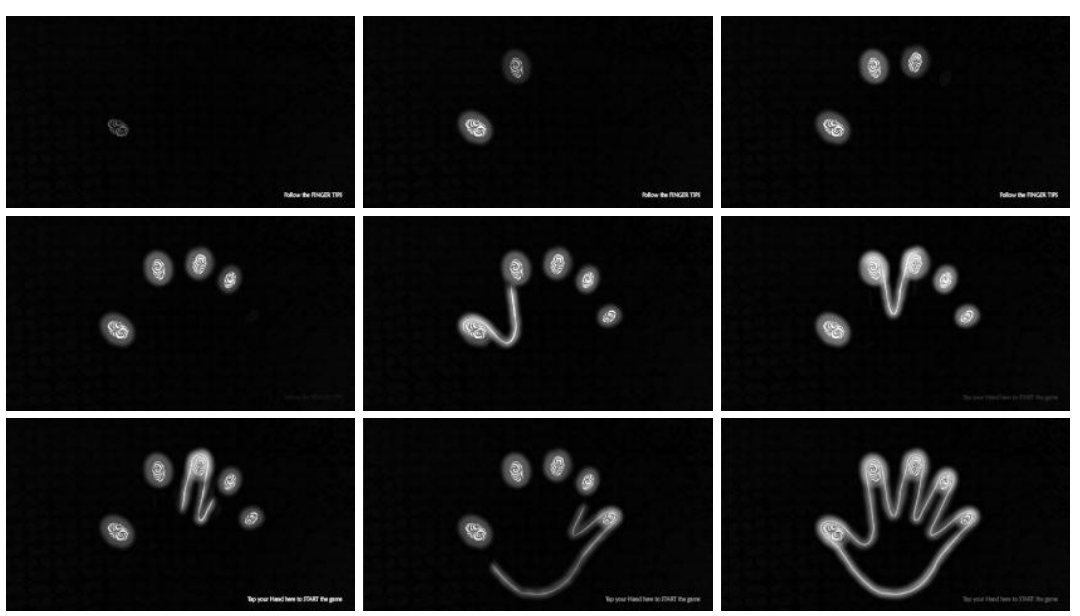

Gambar 6 Deret animasi menu pembuka game NITIKI yang mengambil mekanisme sentuhan lima jari, dan telapak tangan untuk memulai game NITIKI. (dokumen pribadi) 
Proses start dan login game NITIKI diawali oleh tampilan bulatan menyerupai sidik jari sebagai interpretasi dari sentuhan jari. Bulatan yang berkedip hendaklah diikuti oleh sentuhan ujung jari sesuai urutan (ibu jari, telunjuk, tengah, manis, dan kelingking) sebagai syarat membuka kunci tampilan game (terdapat instruksi yang mengikuti setiap adegan animasi) hingga akhirnya membentuk sebuah citra telapak tangan secara utuh (lihat gambar kanan bawah) yang artinya game sedang melakukan proses loading data dan siap dimainkan dalam hitungan detik.

Menu selanjutnya adalah tampilan instruksi yang memberikan informasi kepada pemain tentang bagaimana cara bermain di konsol dengan gameplay tersebut, serta informasi-informasi lainnya yang harus diperhatikan seperti menu keluar, reward and punishment, menyimpan data, sejarah, credits title, bonus, trailer game, dan informasi seputar dunia batik tradisional di pulau Jawa sebagi pembentuk konsep desain game dan gameplay NITIKI. Tampilan pada seksi ini dapat dengan mudah dilangkahi dan berlanjut pada gameplay pertama yaitu canting (Gambar 7).

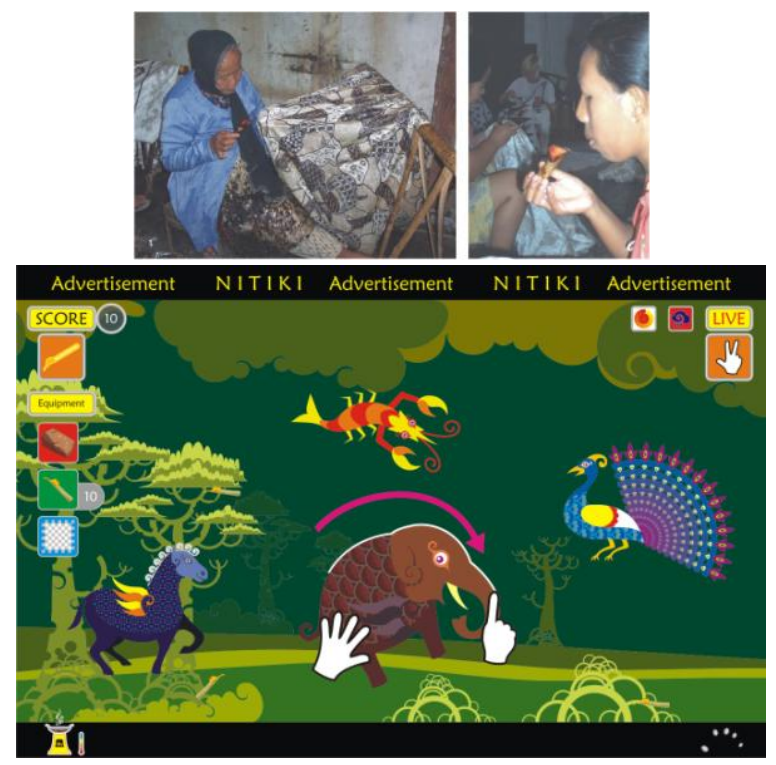

Gambar 7 (ki-ka): Proses membatik tulis tangan menggunakan canting sebagai perintang warna diadaptasi mekanismenya sebagai salah satu cerita pada desain Game Batik NITIKI; rekam gambar gameplay canting. (dokumen pribadi)

Bagian canting, adalah bagian awal dan memiliki tingkat keragaman tantangan dalam game NITIKI. Canting adalah alat untuk membatik tulis terbuat dari tembaga atau kuningan dengan malam sebagai tinta yang berguna sebagai pembentuk motif dan juga sebagai perintang warna kain. Hasil men-canting 
(isen, klowong, nembok) adalah berwarna putih kain atau warna yang lebih terang dari pada warna lain dalam satu kain batik.

Melalui mekanisme dan identifikasi tersebut, maka bagian canting pada game mengadapatasi pola kerja dan hasil karya proses mencanting untuk direduksi menjadi tema utama game NITIKI. Tugas pada fase ini adalah menangkap sebanyak-banyaknya objek berbentuk binatang, bunga yang bergerak dinamis untuk diberi garis terluar dengan memerhatikan waktu permainan, temperatur kompor (anglo) dan jumlah malam pada wajan, serta cuaca. Setiap objek yang berhasil diberi garis luar (warna putih) akan berubah menjadi hidup (animasi), misalkan gajah yang menggoyangkan belalainya, bunga yang bertaburan.

Bagian cap, adalah bagian yang mengidentifikasikan proses pengecapan kain batik dengan menggunakan pola tertentu. Pola pengecapan dapat dilakukan secara acak (batik modern) ataupun menggunkan cara lama (berurut, seperti pola susun bata satu atau bata setengah). Pola permainan ini adalah memilih objek berwarna yang bergerak kemudian ditangkap dan upayakan untuk meletakkannya sesuai pola objek tanpa warna (garis luar putih) yang sejenis bentuk siluetnya. Pemain dapat melakukan perubahan arah (rotasi) dan ukuran (skala) untuk menyesuaikan target (Gambar 8).

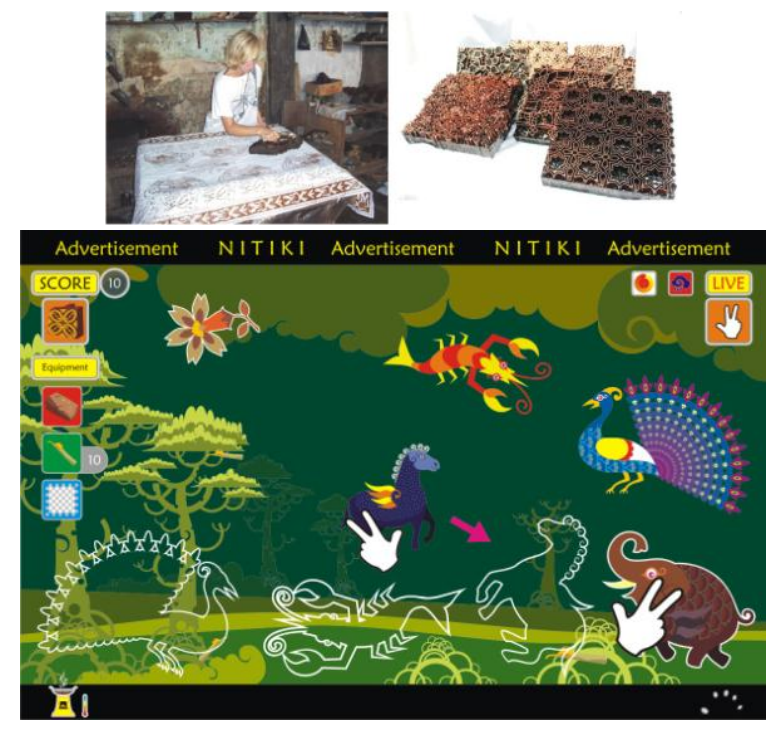

Gambar 8 (ki-ka): Proses membatik cap menggunakan canting cap sebagai perintang warna diadaptasi mekanismenya sebagai salah satu cerita pada desain Game Batik NITIKI; rekam gambar gameplay cap dengan pendekatan puzzle. (dokumen pribadi) 
Lorod, adalah bagian yang mengidentifikasikan proses peluruhan/penghilangan malam dari permukaan kain menggunakan air dengan suhu tinggi (mendidih) sebagai akhir dari proses pembuatan kain tradisional. Proses lorod pada game menggunakan kontrol sentuhan melalui satu hingga beberapa telapak tangan untuk melakukan gerakan menghapus citra lapisan terdepan agar mendapatkan tampilan kain batik motif tertentu yang telah diatur acak oleh program yang tersembunyi di balik latar depan (Gambar 9).

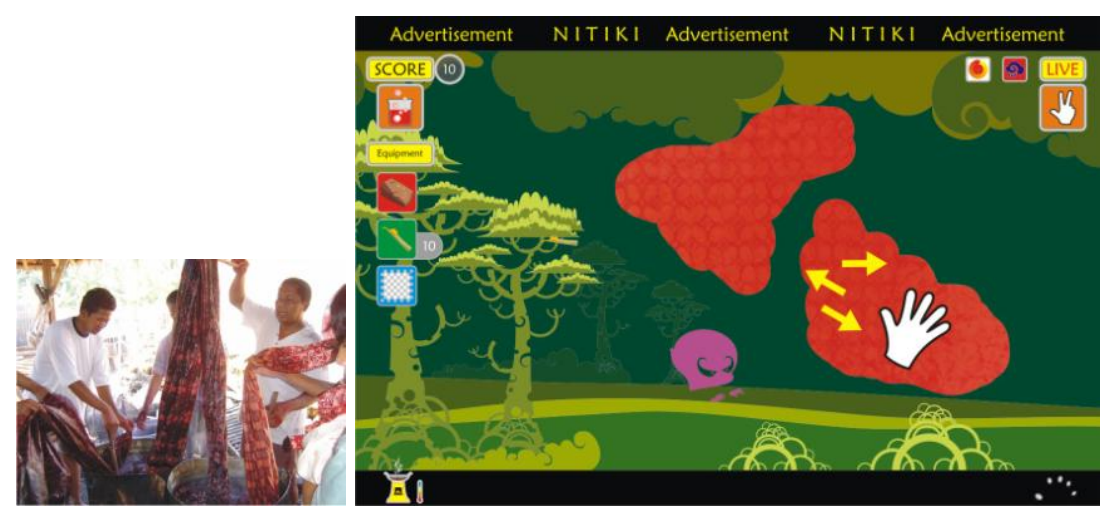

Gambar 9 (ki-ka): Proses menghilangkan malam batik yang disebut me-lorod diadaptasi mekanismenya sebagai salah satu cerita pada desain Game Batik NITIKI; rekam gambar gameplay lorod. (dokumen pribadi)

Bagian lorod menandai bahwa keseluruhan gameplay NITIKI dan cerita yang dipesankan selesai dan beralih pada menu yang menampilkan informasi poin dan bonus yang terkumpul serta reward yang akan didapat sebagai imbalan menyelesaikan tugas-tugas yang disuguhkan oleh game NITIKI.

Tampilan terakhir dari keseluruhan gameplay adalah daftar perancang dari sutradara, produser, artisan, dan seluruh pihak yang telah mendukung proses perancangan game batik NITIKI serta ucapan terima kasih.

\section{$6 \quad$ Kesimpulan}

Perancangan game digital sebagai media informasi pendidikan memerlukan upaya yang cukup mendalam, yaitu dengan menelaah dan memilah jenis game yang telah ada, muatan tema sebagai pembangun gameplay, cerita dan pesan, teknologi game yang menyertai, target audiens, dan rencana penempatan konsol game di wilayah tertentu. 

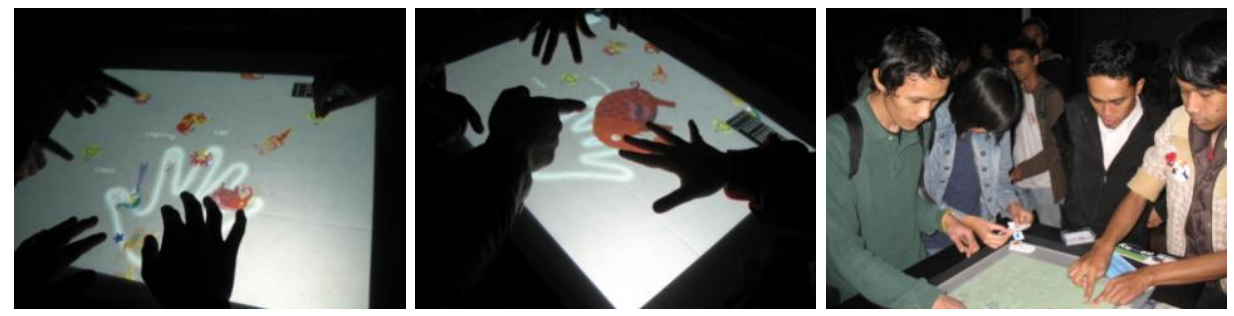

Gambar 10 (ki-ka): Tampak beberapa dokumentasi pada uji coba prototip Game Batik "NITIKI" berteknologi Multi-Touch Screen pada acara PechaKuchaNight di Bandung, 8 Agustus 2008. (dokumen pribadi)

Perancangan game dengan batik tradisonal di pulau Jawa sebagai muatan cerita perlu disosialisasikan sebagai upaya pelestarian batik tradisonal di pulau Jawa ke dalam medium game digital. Artinya batik tradisonal mampu bergerak beriringan, bersinggungan, dan saling mengisi keterbatasan di masing-masing disiplin ilmu. Perancangan game ini pulas ebagai bentuk kepedulian terhadap lintas disiplin ilmu-seni-teknologi dalam satu bentuk kegiatan penelitian dan perancangan yang mecoba untuk mengikis batas-batas ego masing-masing disiplin untuk dileburkan menjadi satu bentuk kajian dan karya yang dapat dimanfaatkan secara langsung oleh masyarakat di Indonesia dari skala kecil hingga besar.

Proses penelitian dan perancangan memiliki beberapa kendala terutama yang menyangkut kandungan nilai antara dunia batik tradisional, persinggungannya dengan mekanisme teknologi multi-touch screen dan dunia game digital yang bersifat edutainment. Proses reduksi hingga deformisasi bentuk rupa adalah beberapa upaya untuk tetap mempertahankan konsep penggabungan displin budaya tradisi dan modern tanpa menghilangkan kaidah-kaidah yang telah dibentuk oleh kajian sebelumnya.

Dalam perkembangannya, game batik NITIKI sebagai salah satu pelopor game digital bermuatan budaya tradisi adalah sebuah hasil kajian dan rancangan yang masih perlu dilakukan perbaikan dan telaah lebih lanjut untuk menjadi sebuah produk penelitian yang layak dikonsumsi oleh masyarakat. Adapun uji coba prototip adalah suatu bentuk dalam menjaring data lanjutan tentang mekanisme, gameplay, citra rupa, kesan yang dirasakan oleh audiens sebagai masukan untuk proses perancangan optimal (Gambar 10).

Upaya penelitian dan perancangan game batik NITIKI berteknologi multi-touch screen dapat menjadi inspirasi bagi banyak kalangan dalam turut serta melestarikan budaya tradisi Indonesia yang melebur dalam media teknologi lainnya. 


\section{Referensi}

[1] Kayam, Umar. 2000. Pertunjukan Rakyat Tradisional Jawa dan Perubahan, dalam Heddy Shri Ahimsa-Putra (ed.), Ketika Orang Jawa Nyeni, Yayasan Adikarya IKAPI dan Ford Foundation, Yogyakarta.

[2] Yahya, Amri. 1985. Sejarah Perkembangan Seni Lukis Batik Indonesia, Javanologi, Yogyakarta.

[3] Produk Batik Jadi Andalan Penghasil Devisa, http://www.depkominfo.go.id.

[4] Hasanuddin. 2001. Batik Pesisiran, Melacak Pengaruh Etos Dagang Santri pada Ragam Hias Batik, Kiblat, Bandung.

[5] Wand, Eku. 2007. Interactive Storytelling-Making of Berlin Connection, Bandung, 18 September 2007.

[6] Adlin, Alfathri. 2007. Spiritualitas dan Realitas Kebudayaan Kontemporer, Jalasutra, Yogyakarta.

[7] Rouse III, Richard. 2000. Game Design, Theory and Practise, Wordware Publishing, Inc, Texas.

[8] Yahya, Amri. 1985. Pengetahuan Dasar Membatik, Seminar-Depdikbud, Jakarta, 1985.

[9] Edelson, Mary Jane \& Damais, Soedarmadji J.H. 1990. Sekaring Jagad Ngayogyakarta Hadiningrat, Wastraprema, Jakarta.

[10] Susanto, S.K. Sewan S. Teks . 1981. Teknologi Batik seri Soga Batik, Departemen Perindustrian RI-Balai Penelitian dan Pengembangan Industri Balai Besar Penelitian dan Pengembangan Industri Kerajianan dan Batik, Yogyakarta.

[11] Kudiya, Komarudin, Sunarya, Yan Yan \& Tresnadi, Chandra. 2005. Motif Batik, Batik \& Tenun, Perspektif Industri dan Dagang, DEPPERIN RI. 